Int. J. Morphol.,

29(2):562-567, 2011

\title{
Estereología de la Glándula Tiroides Humana
}

\author{
Stereology of the Human Thyroid Gland
}

${ }^{*, * *}$ Guillermo Salgado A; ${ }^{* * *}$ Bélgica Vásquez; ${ }^{* * * *}$ Mariano del Sol

SALGADO, A. G.; VÁSQUEZ, B. \& DEL SOL, M. Estereología de la glándula tiroides humana. Int. J. Morphol., 29(2):562-567, 2011.

RESUMEN: La glándula tiroides es una glándula endocrina voluminosa, impar, mediana y simétrica, que ocupa la parte anterior del cuello, en la unión del tercio inferior con los dos tercios superiores. La unidad funcional y estructural de la glándula tiroides es el folículo tiroideo. Los folículos están separados unos de otros por escaso tejido conectivo interfolicular. Se ha observado en modelos experimentales animales, diversos valores estereológicos de células foliculares, parafoliculares y coloide. El objetivo del trabajo fue determinar si existe un patrón estereológico en la glándula tiroides humana en un grupo etáreo y sexo definidos. Para ello, se ocupó una muestra de 6 glándulas tiroides humanas extraidas de cadáveres no fijados, de individuos adultos de sexo masculino, sin antecedentes de patología o alteración tiroídea. Se procesaron histológicamente con H-E para su estudio estereológico. Los resultados mostraron valores promedio para la densidad de volumen del tejido glandular $(33,8 \%)$ y del coloide $(63,17 \%)$, densidad de superficie del folículo tiroídeo $\left(21,09 \mathrm{~mm}^{2} / \mathrm{mm}^{3}\right)$, densidad de número de células foliculares $\left(10,81 \times 10^{5}\right.$ células $\left./ \mathrm{mm}^{3}\right)$ y parafoliculares $\left(1,81 \mathrm{x} 10^{5}\right.$ células $\left./ \mathrm{mm}^{3}\right)$. Conocido el volumen promedio de la glándula $\left(21,3 \mathrm{~mm}^{3}\right)$, se determinó el número total de células foliculares $\left(230,22 \mathrm{x} 10^{5}\right)$ y parafoliculares $\left(38,33 \times 10^{5}\right)$. Además, se determinó el número de folículos por $\mathrm{mm}^{2}\left(46,18\right.$ folículos $\left./ \mathrm{mm}^{2}\right)$. El conocimiento previo de los valores numéricos y proporciones normales estereólogicos permite establecer parámetros que determinen la alteración hiper o hipotrófica de origen endémico o exógeno que lleven a estratificar ciertas alteraciones, hecho observado en modelos experimentales donde las diferencias son significativas.

PALABRAS CLAVE: Glándula tiroides; Morfología; Estereología.

\section{INTRODUCCIÓN}

El nombre de glándula tiroides proviene del término griego Thyreos que significa escudo (Stathatos, 2006). Es una glándula endocrina voluminosa, impar, mediana y más o menos simétrica que ocupa la parte anterior del cuello, en la unión del tercio inferior con los dos tercios superiores. Compuesta de una porción mediana, relativamente estrecha, el istmo y dos partes laterales voluminosas, los lóbulos relacionados con los anillos traqueales $5^{\circ}$ y $6^{\circ}$.

La unidad funcional y estructural de la glándula tiroides es el folículo tiroideo. Los folículos están separados unos de otros por escaso tejido conectivo interfolicular. Estos folículos están constituidos por un epitelio cúbico simple que rodea a un espacio que contiene a una sustancia viscosa, el coloide. Los folículos varían de tamaño desde 50 $\mu \mathrm{m}$ hasta $1 \mathrm{~mm}$ de diámetro constituidos por células foliculares y células $\mathrm{C}$, las cuales se encuentran hacia la luz y hacia la base del folículo respectivamente, siendo el coloide producto de las células foliculares, por lo cual se trata de un almacenamiento extracelular (Geneser, 2005). En ratas se ha observado que el tamaño de un folículo depende del número de células y cantidad de coloide, estos elementos interactúan entre sí de manera dependiente, existiendo una correlación del volumen total de coloide con el número de folículos y el área de superficie del tejido conectivo interfolicular, lo cual implica que, en condiciones fisiológicas normales, existe un equilibrio en la cantidad y distribución del volumen de coloide en cada folículo (Hartoft-Nielsen et al., 2005). Se ha contabilizado con métodos estereológicos la cantidad de células $\mathrm{C}$ presentes en la glándula tiroides de rata encontrando un número equivalente en ambos lóbulos (Feinstein et al., 1996).

\footnotetext{
* Departamento de Anatomía, Pontificia Universidad Católica de Chile

** Facultad de Ciencias de la Salud, Universidad Autónoma de Chile, Temuco, Chile

**** Univesidad de La Frontera, Temuco, Chile.

***** Programa de Magíster en Ciencias, Mención Morfología, Universidad de La Frontera, Chile
} 
Se han descrito en modelos experimentales en ratas que existen diversos factores que alteran la proporcionalidad entre coloide y tejido glandular (Sekulic et al., 2005) y además entre las células parafoliculares y foliculares del tejido (Feinstein et al.; Rognonil et al.,1989; Rajkovic et al., 2010).

Se ha observado gran variablidad de acuerdo a sexo y edad en modelos experimentales animales (Sosic'-Jurjevic' et al., 2006; Erdem et al., 2011) por lo que la determinación de un rango y valores estándares ha sido una tarea ardua en las diferentes especies que hace especialmente engorrosa la recolección de datos en glándulas humanas.

El objetivo del estudio, fue determinar, a través de la estereología, aspectos cuantitativos en la glándula tiroides humana en un grupo etáreo y sexo definido. Con la generación de estos nuevos conocimientos será posible sentar las bases para futuras investigaciones morfofuncionales

\section{MATERIAL Y MÉTODO}

Utilizamos 6 glándulas tiroides humanas, obtenidas de cadáveres no fijados, mantenidos en cámaras frigoríficas a $0^{\circ} \mathrm{C}$, de individuos adultos de sexo masculino, sin antecedentes de patología o alteración tiroídea. Para la obtención de las muestras, se disecó la zona cervical extirpando las glándulas tiroides completamente.

Posteriormente, se determinó el volumen de las glándulas a partir de la variación de peso del sistema propuesto por Scherle (1970) y recomendado por Mandarim-deLacerda (1995). Obtuvimos 5 trozos aleatoriamente del lóbulo izquierdo de cada glándula, considerando las caracte- rísticas isotrópicas del tejido. Luego, las secciones fueron fijadas en formalina tamponda al $10 \% \mathrm{pH} 7,4$ y procesadas siguiendo el protocolo convencional para su inclusión en parafina.

Se efectuaron cortes seriados de $4 \mu \mathrm{m}$ de grosor, los que fueron teñidos con H.E. Luego, analizamos 5 campos de cada corte histológico, 125 campos microscópicos en total por glándula. Las láminas fueron observadas en un microscopio Olympus ${ }^{\circledR}$, modelo CX 31, con una cámara Moticam ${ }^{\circledR}$. Las imágenes fueron proyectadas en un monitor de pantalla plana Sony®. Se utilizó el test multipropósito M42. Los parámeros estereológicos medidos fueron: densidad de volumen $\left(\mathrm{V}_{\mathrm{v}}\right)$, para el tejido glandular y para el coloide del folículo tiroideo, la densidad de superficie $\left(\mathrm{S}_{\mathrm{v}}\right)$ del folículo, el número de células glandulares foliculares y parafoliculares a través de la densidad de número $\left(\mathrm{N}_{\mathrm{v}}\right)$, aplicando el método disector y el número total $\left(\mathrm{N}_{\mathrm{T}}\right)$ de células foliculares y parafoliculares de cada glándula. Además, se determinó el número de folículos tiroídeos por $\mathrm{mm}^{2}$ mediante planimetría sobre un área calibrada $\left(\mathrm{a}^{2}\right)$ de $0,068 \mathrm{~mm}^{2}$. Se calcularon, el promedio, la desviación estándar, el error estándar, el coeficiente de variación y el coeficiente de error. Se consideró un índice de significancia menor o igual a 0,05.

\section{RESULTADOS}

El porcentaje promedio del tejido glandular y del coloide de la glándula tiroides fue de un $33,08 \%$ (D.E. 4,8) y $63,17 \%$ (D.E. 7,25) respectivamente. El porcentaje de tejido glándular y de coloide de las 6 muestras se presenta en la Figs. 1 y 2. En la Tabla I se muestra el análisis estadísticos para Vv del tejido glandular y del coloide de la glándula tiroides.

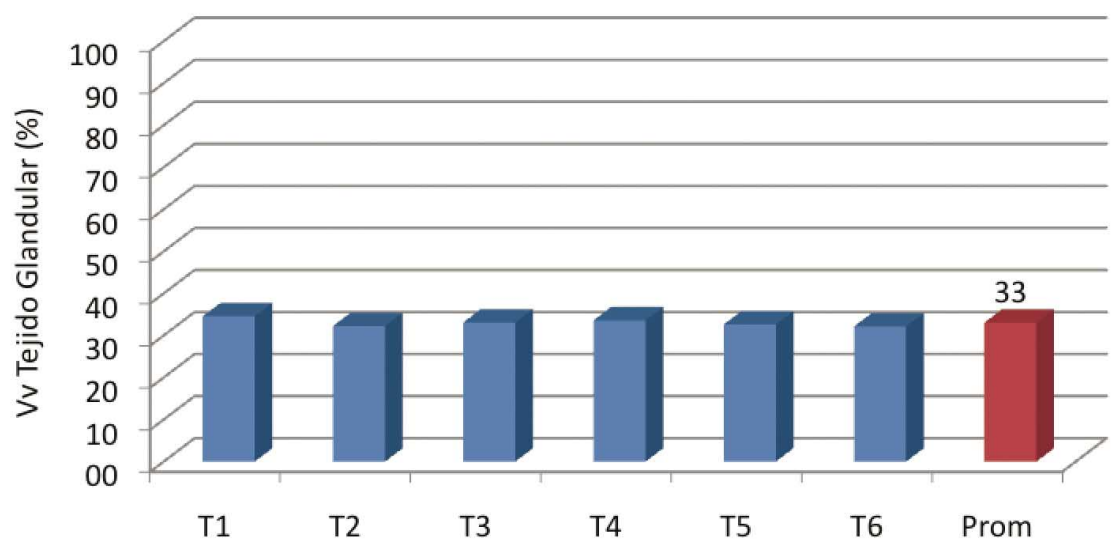

Fig. 1. Porcentaje de tejido glandular de las 6 muestras de glándula tiroides. 


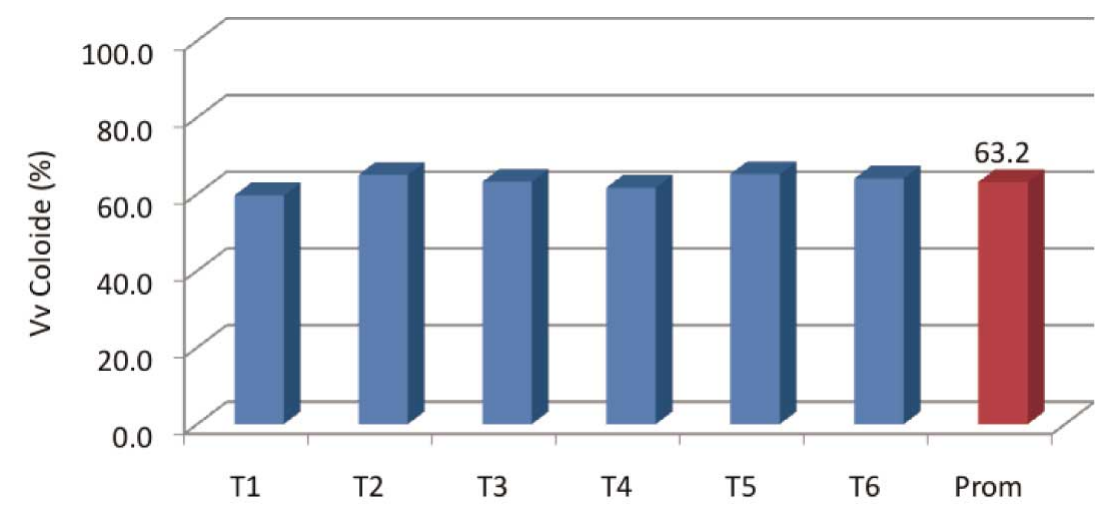

Fig. 2. Porcentaje de coloide de las 6 muestras de glándula tiroides.

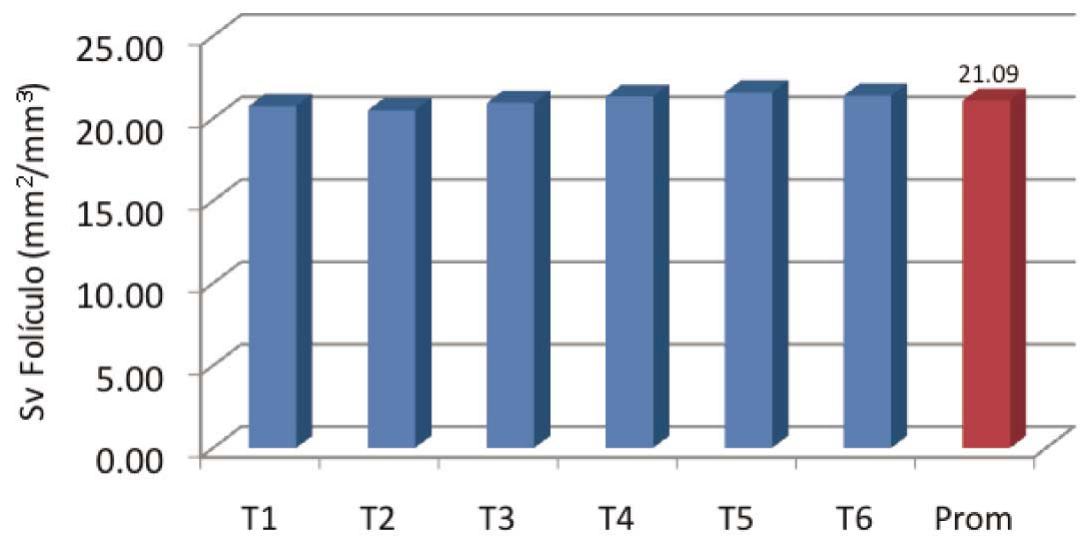

Fig. 3. Densidad de superficie del folículo de las 6 muestras de glándula tiroides.

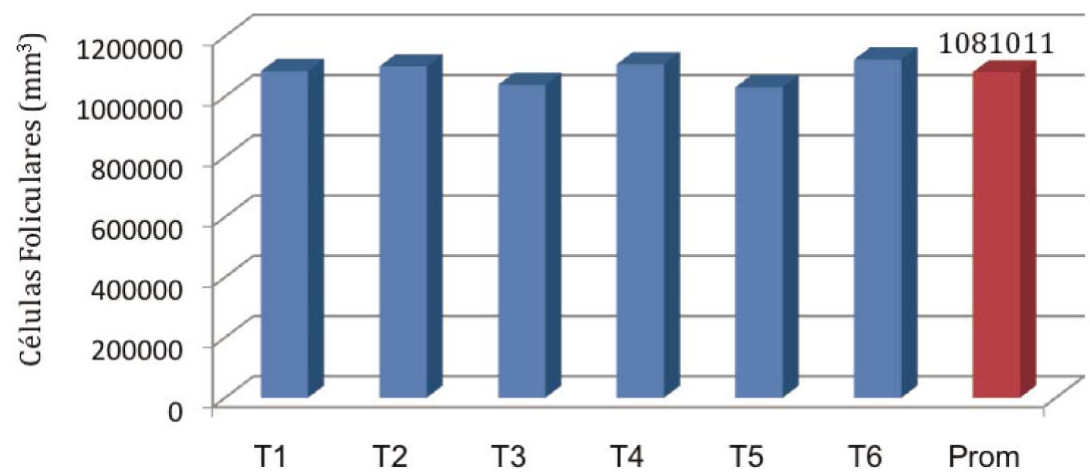

Fig. 4. Densidad de número de células foliculares de las 6 muestras de glándula tiroides.
El promedio de Sv de folículos tiroídeos fue de $21,09 \mathrm{~mm}^{2} / \mathrm{mm}^{3}$ (D.E. 2,95). El límite inferior fue $17,83 \mathrm{~mm}^{2} /$ $\mathrm{mm}^{3}$ y el superior de $24,75 \mathrm{~mm}^{2} / \mathrm{mm}^{3}$. El error estándar fue $1,2 \mathrm{~mm}^{2} / \mathrm{mm}^{3}$; el coeficiente de variación fue de $13,98 \%$ y el coeficiente de error fue $5,71 \%$. La Sv folicular para cada muestra se presenta en la Fig. 3.

El promedio de células foliculares y parafoliculares de la glándula tiroides fue de $10,81 \times 10^{5}$ células $/ \mathrm{mm}^{3}$ (D.E. $0,59)$ y $1,81 \times$ x $10^{5}$ células $/ \mathrm{mm}^{3}$ (D.E. $0,18)$ respectivamente. La Nv de células foliculares y parafoliculares de la glándula tiroides se muestra en las Figs. 4 y 5. En la Tabla II se observa el análisis estadísticos para la Nv de células foliculares y parafoliculares de la glándula tiroires.

El volumen promedio de la glándula tiroides fue $21,3 \mathrm{~mm}^{3}$ (D.E. 1,11) . El número total de células foliculares para la glándula tiroides fue en promedio $230,22 \times 10^{5}$ (D.E. $13,91 \times 10^{5}$ ) y el de células parafoliculares fue en promedio $38,33 \times 10^{5}$ (D.E. $2,42 \times 10^{5}$ ). Fig. 6.

El promedio de folículos tiroideos fue 3,14 folículos $/ a^{2}$ (D.E. 0,42). La cantidad mínima fue 2,68 folículos/a $/ \mathrm{a}^{2}$ y la máxima 3,64 folículos/a ${ }^{2}$. El error estándar fue 0,17 folículos/a ${ }^{2}$; el coeficiente de variación fue $13,47 \%$ y el coeficiente de error fue $5,5 \%$.

Conocida $a^{2}$, el promedio de folículos tiroideos fue 46,18 folículos/ $\mathrm{mm}^{2}$ (D.E. 1.61). La cantidad mínima fue 44,7 folículos $/ \mathrm{mm}^{2}$ y la máxima 48,82 folículos $/ \mathrm{mm}^{2}$. El error estándar fue 0,66 folículos $/ \mathrm{mm}^{2}$; el coeficiente de variación fue $3,48 \%$ y el coeficiente de error fue $1,42 \%$. (Fig. 7).

Tabla I. Densidad de volumen promedio del tejido glandular y del coloide de la glándula tiroides.

\begin{tabular}{lcccccccc}
\hline Vv & $\begin{array}{c}\text { Promedio } \\
(\%)\end{array}$ & D.E. & $\begin{array}{c}\text { Mínimo } \\
(\%)\end{array}$ & $\begin{array}{c}\text { Máximo } \\
(\%)\end{array}$ & $\begin{array}{c}\text { E.E. } \\
(\%)\end{array}$ & $\begin{array}{c}\text { C.V. } \\
(\%)\end{array}$ & $\begin{array}{c}\text { C.E. } \\
(\%)\end{array}$ & Valor de p \\
\hline $\begin{array}{l}\text { Tejido } \\
\text { glandular }\end{array}$ & 33,08 & 4,8 & 27,49 & 39,05 & 1,96 & 14,52 & 5,92 & 0,61 \\
\begin{tabular}{l} 
Coloide \\
\hline
\end{tabular} & 63,17 & 7,25 & 54,51 & 72,06 & 2,65 & 11,46 & 4,68 & 0,14 \\
\hline
\end{tabular}




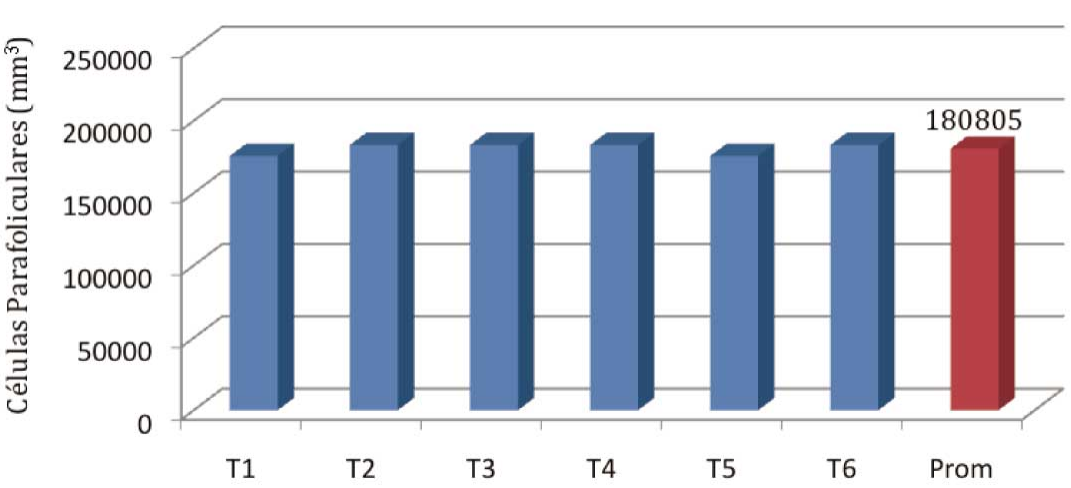

Fig. 5. Densidad de número de células parafoliculares de las 6 muestras de glándula tiroides.

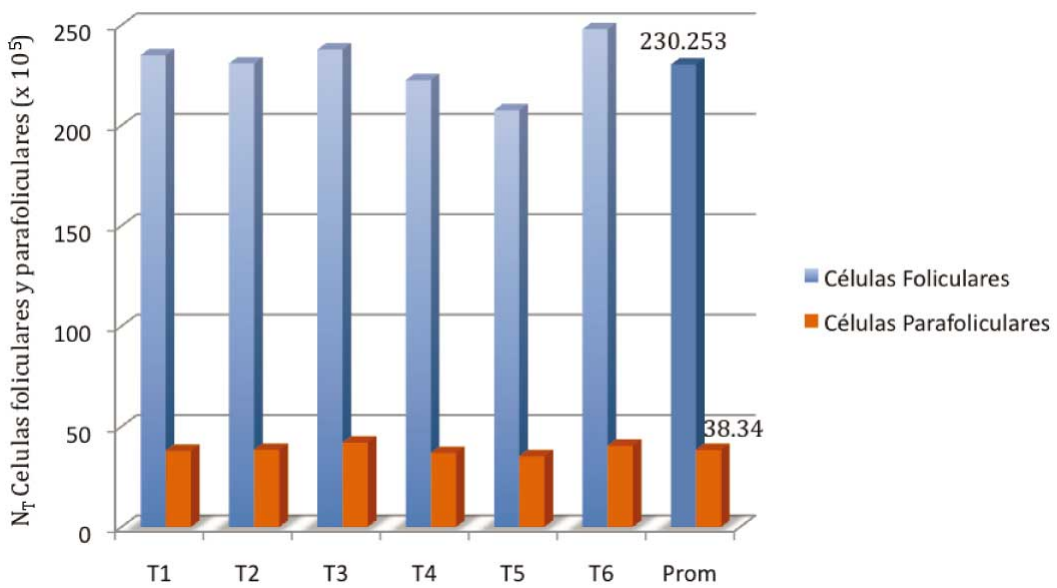

Fig. 6. Número total (NT) de células foliculares y parafoliculares de la glándula tiroides.

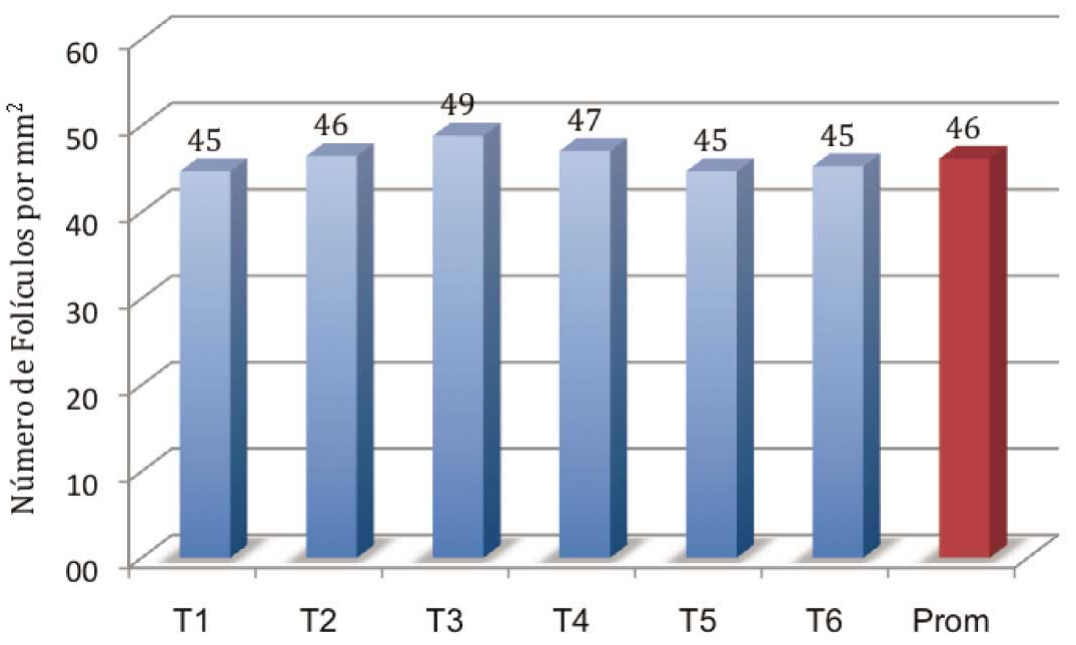

\section{DISCUSIÓN}

Estudios estereológicos de la glándula tiroides humana son escasos, siendo necesario comparar este estudio con aquellos realizados en animales.

El número promedio de células parafoliculares de la glándula tiroides humana fue de $1,81 \times 10^{5}$ células $/ \mathrm{mm}^{3}$; con un rango de 1,52-1,9 x $10^{5}$ células/ $\mathrm{mm}^{3}$. Estos valores son comparables a los obtenidos por Feinstein et al., quienes a través del método disector-fraccionador óptico, determinaron que la glándula tiroides de ratas tiene $185.000 \pm 42.000$ células parafoliculares. Para ellos, la población de células parafoliculares no difiere significativamente entre los lóbulos, lo cual confirma la característica isotrópica del tejido glandular.

Según Feinstein et al., las técnicas de conteo 2-D utilizadas en estudios estereológicos están sesgadas debido a que el tamaño y la forma de las estructuras contadas, así como los cambios dimensionales de las secciones durante la preparación histológica, pueden influenciar los resultados del recuento. La razón, es que una partícula que es dos veces mayor que otra tiene también dos veces más oportunidad de estar presente en la sección (Gundersen et al., 1988). Esto podría superarse con la utilización de métodos 3-D con el disector óptico, que anula el error de tamaño, independientemente de la forma celular, la orientación y los cambios dimensionales. Este margen de error, se ve disminuido en la glándula tiroides debido a su característica isotrópica.

Fig. 7. Número de folículos de las 6 muestras de glándula tiroides por $\mathrm{mm}^{2}$.

Tabla II. Densidad de número promedio de células foliculares y parafoliculares de la glándula tiroides.

\begin{tabular}{|c|c|c|c|c|c|c|c|c|}
\hline $\mathrm{Nv}$ & $\begin{array}{c}\text { Promedio } \\
\text { (células } / \mathrm{mm}^{3} \text { ) }\end{array}$ & D.E. & $\begin{array}{c}\text { Mínimo } \\
\text { (células/mm) }\end{array}$ & $\begin{array}{c}\text { Máximo } \\
\text { (células/mm³) }\end{array}$ & $\begin{array}{c}\text { E.E. } \\
\text { (células } / \mathrm{mm}^{3} \text { ) }\end{array}$ & $\begin{array}{l}\text { C.V. } \\
(\%)\end{array}$ & $\begin{array}{l}\text { C.E. } \\
(\%)\end{array}$ & $\begin{array}{l}\text { Valor } \\
\text { de p }\end{array}$ \\
\hline $\begin{array}{l}\text { Células } \\
\text { foliculares }\end{array}$ & $10,81 \times 105$ & 0,59 & $10,12 \times 10^{5}$ & $11,27 \times 105$ & $0,24 \times 10^{5}$ & 5,45 & 2,23 & 0,99 \\
\hline $\begin{array}{l}\text { Células } \\
\text { parafoliculares }\end{array}$ & $1,81 \times 10^{5}$ & 0,18 & $1,52 \times 10^{5}$ & $1,9 \times 10^{5}$ & $0,74 \times 10^{5}$ & 10,15 & 4,14 & 0,96 \\
\hline
\end{tabular}


Feinstein et al. señalaron variaciones en los resultados entre ratas. Las razones de estas diferencias interindividuales no se conocen exactamente, pero se podría deber a factores genéticos, como la cepa de rata usada. Este hecho, podría explicar el rango de variación entre 1,52 y 1,9 x $10^{5}$ células $/ \mathrm{mm}^{3}$ encontradas en las glándulas tiroides humanas. Así por ejemplo, componentes étnicos podrían tener influencia en el número de células parafoliculares en humanos.

El conocimiento previo de los valores numéricos y proporciones normales estereológicos de las estructuras que constituyen la glándula tiroides, permite obtener parámetros que determinen la alteración hipo o hipertrófica de origen endémico o exógeno que nos lleven a estratificar ciertas alteraciones. Asímismo, la glándula tiroides se caracteriza porque la función del órgano depende de diveros factores que podrían influir en las características morfológicas y estereológicas de las estructuras que la constituyen.

Estas experiencias, han sido observadas en modelos experimentales en ratas. Sekulic et al., estudiaron las características de las células parafoliculares y foliculares de la tiroides en ratas hembras después del tratamiento con calcitonina sintéticade salmón. Los resultados presentados en esa investigación, apoyan y confirman que el tratamiento crónico de ratas hembras adultas con dosis diferentes calcitonina reducen los parámetros estructurales de las células parafoliculares, y mejoran las de las células foliculares tiroideas en forma dosis-dependiente. Nuestros resultados muestran un porcentaje promedio del tejido glandular de la glándula tiroides humana de un 33,08\% y el porcentaje promedio del coloide de un 63,17\%. Observamos además, una proporción inversa de tejido glandular v/s coloide.

Rognonil et al. estudiaron los cambios en el volumen de células foliculares tiroideas en la involución temprana del bocio hiperplásico utilizando ratas Wistar macho a las cuales se les administró una dieta deficiente en yodo durante 6 meses. Observaron un aumento en el volumen de las células foliculares, casi al doble, en relación a los controles, retornando a valores similares 16 días posteriores a la incorporación de yodo en la dieta.

Por otro lado, el aumento de la prevalencia de neoplasias a nivel cervical, ha llevado al uso de variados tratamientos de quimioterapia y de ondas de alta y baja frecuencia, que podrían afectar directamente la morfología de la glándula tiroides. Rajkovic et al. (2003) reportaron en ratas sometidas a campos electromagnéticos de $50 \mathrm{~Hz}$ por 3 meses, un aumento significativo en la $\mathrm{Vv}$ de los folículos tiroideos y del coloide, mientras que la $\mathrm{Vv}$ del epitelio glandular no mostró gran diferencia con los controles y la $\mathrm{Vv}$ del tejido interfolicular disminuyó de un $12,4 \%$ en los con- troles a un $8,8 \%$ en el grupo esperimental. Observaron disminución en la Nv de células parafoliculares tiroideas en ratas de dos días post natal expuestas campos electromagnéticos de $50 \mathrm{~Hz}$ por 3 meses.

Nuestros resultados señalan un promedio de células foliculares de $10,81 \times 10^{5}$ células $/ \mathrm{mm}^{3}$ y de células parafoliculares de $1,81 \times 10^{5}$ células $/ \mathrm{mm}^{3}$ es decir en una proporción de 10:1. En cambio, los estudios de Rognonil et al. entregan valores de 59,6 × $10^{9}$ células foliculares por $\mathrm{mm}^{3}$ y Rajkovic et al. (2010) 61,91 x $10^{9}$ células parafoliculares, valores muy similares entre ellos pero para células diferentes, lo cual podría deberse al uso de cepas distintas de ratas (Feinstein et al.) lo que reafirma la diferencia de actividad e importancia metabólica que presenta la glándula en las distintas especies y más aún en el hombre.

Sosic'-Jurjevic' et al. estudiaron los efectos de la ovariectomía y la administración de estradiol crónico sobre el eje hipófisis-tiroideo en ratas adultas mediante el método estereológico para determinar la $\mathrm{Vv}$ del tejido glandular en la tiroides. La ovariectomía influyó en la Vv de los folículos y el coloide con mayor intensidad en la zona central que en el zona periférica de tiroides mostrando $\mathrm{Vv}$ de los folículos y el coloide con un aumento de $20 \%$ y $55 \%$ respectivamente. $\mathrm{La} \mathrm{Vv}$ del intersticio disminuyó en un $24 \%$, mientras que la $\mathrm{Vv}$ del epitelio folicular no cambió significativamente en comparación con el control. Esto resulta interesante y deja abierta la opción de realizar esterología en glándulas tiroides humanas en mujeres de diversas edades (pre y post menopáusica) para ver si el comportamiento es similar al observado en estudios experimentales.

Recientemente Erdem et al. compararon la expresión de la COX-2, E-cadherina, VEGF como factor pronóstico en términos de la intensidad de tinción mediante la estereología en pacientes con carcinoma papilar de tiroides para ser utilizados como indicadores de pronóstico. Utilizaron el método disector sobre muestras teñidas con inmunohistoquímica para el VEGF, la COX-2 y la Ecadherina a partir de resecciones o biopsias tiroídeas. Concluyeron que en consonancia con la literatura, existió una relación significativa entre la edad, el sexo y el aumento de VEGF, la expresión de COX-2 en estadio avanzado. Además, a pesar de la existencia de una relación entre un parámetro de mal pronóstico por multifocalidad y la intensidad de tinción, no se encontró significación estadística. Cuando se evaluó la expresión de E-cadherina con la edad, se encontró que existe una relación con la intensidad de la tinción. Esto nos motiva a realizar estudios por rangos de edad de glándulas tiroides y así poder comparar, analizar y estratificar pronósticos de ciertas patologías con nuestros datos obtenidos. 
SALGADO, A. G.; VÁSQUEZ, B. \& DEL SOL, M. Stereology of the human tyroid gland. Int. J. Morphol., 29(2):562-567, 2011.

SUMMARY: The thyroid gland is a an extensive, medium and symmetrical endocrine gland situated on the anterior side of the neck at the lower third and the upper third junction. The thyroid follicle is the functional and structural unit of the thyroid gland. Follicles are separated from each other by narrow interfollicular connective tissue. Stereological values of follicular, parafollicular and colloid containing follicles have been observed in experimental animal models. The aim of this study was to determine the existence of a stereological pattern in the human thyroid gland defined by age and sex. A sample of six human thyroid glands of adult males with no history of thyroid disease or disorder obtained from non fixed human cadavers; of these cadavers the gland was removed and processed for thyroid follicle density $\left(21.09 \mathrm{~mm}^{2} / \mathrm{mm}^{3}\right)$, follicular cell number density $\left(10.81 \times 10^{5}\right.$ cells/mm $\left./ \mathrm{m}^{3}\right)$ and parafollicular $\left(1.81 \times 10\right.$ cells $\left./ \mathrm{mm}^{3}\right)$. With the average gland volume $\left(21.3 \mathrm{~mm}^{3}\right)$ we determined the total number of follicular cells $\left(230.22 \times 10^{5}\right)$ and parafollicular $\left(38.33 \times 10^{5}\right)$. The number of follicles per $\mathrm{mm}^{2}\left(46.18\right.$ follicles $\left./ \mathrm{mm}^{2}\right)$ was also determined. Prior information and knowledge of numerical values and normal stereological proportions provides excellent parameters for determining hyper or hypotrophic endemic or exogenous alterations leading to stratification of certain disorders which was already observed in experimental models where differences amongst models were significant.

KEY WORDS: Thyroid gland; Morphology; Stereology.

\section{REFERENCIAS BIBLIOGRÁFICAS}

Erdem, H.; Gündogdu, C. \& Sipal, S. Correlation of E-cadherin, VEGF, COX-2 expression to prognostic parameters in papillary thyroid carcinoma. Exp. Mol. Pathol., 90(3):3127, 2011.

Feinstein, R. E.; Westergren, E.; Bucht, E.; Sjöberg, H. E. \& Grimelius, L. Estimation of the C-cell numbers in rat thyroid glands using the optical fractionator. J. Histochem. Cytochem., 44(9):997-1003, 1966.

Geneser, F. Histología. $3^{\mathrm{a}}$ ed. Buenos Aires, Médica Panamericana, 2005.

Gundersen, H. J.; Bagger, P.; Bendtsen, T. F.; Evans, S. M.; Korbo, L.; Marcussen, N.; Møller, A.; Nielsen, K.; Nyengaard, J. R. \& Pakkenberg, B. The new stereological tools: disector, fractionator, nucleator and point sampled intercepts and their use in pathological research and diagnosis. APMIS, 96(10):857-81, 1988.

Hartoft-Nielsen, M. L.; Rasmussen, A. K.; Feldt-Rasmussen, U.; Buschard, K. \& Bock, T. Estimation of number of follicles, volume of colloid and inner follicular surface area in the thyroid gland of rats. J. Anat., 207(2):117-24, 2005.

Mandarim-de-Lacerda, C.A. Métodos quantitativos em morfología. Rio de Jameiro, EDUERJ, 1995

Rajkovic, V.; Matavulj, M.; Gledic, D. \& Lazetic B. Evaluation of rat thyroid gland morphophysiological status after three months exposure to $50 \mathrm{~Hz}$ electromagnetic field. Tissue Cell., 35(3):223-31, 2003.

Rajkovic, V.; Matavulj, M. \&Vuckovic D. The effects of chronic exposure to electromagnetic fields on thyroid parafollicular cell in rats. Arch. Biol. Sci., Belgrade, 62 (2):347-9, 2010.
Rognonil, J. B.; Penel, C.; Bastiani, P.; Roccabianca, M. \& Lemarchand-Beraud, T. Down regulation of hypertrophied follicular cell volume in thyroid hyperplastic gland. Histol. Histopathol., 4(2):193-200, 1989.

Sekulic' M, Sosic'-Jurjevic' B, Filipovic' B, Milosevic' V, Nestorovic' N, Manojlovic'-Stojanoski M. The effects of synthetic salmon calcitonin on thyroid $\mathrm{C}$ and follicular cells in adult female rats. Folia Histochem. Cytobiol., 43(2):103$8,2005$.

Scherle, W. A simple method for volumetry of organs in quantitative stereology. Mikroskopie, 26:57-60, 1970.

Sosic'-Jurjevic', B.; Filipovic', B.; Milosevic', V.; Nestorovic', N.; Negic', N. \& Sekulic', M. Effects of ovariectomy and chronic estradiol administration on pituitary-thyroid axis in adult rats. Life Sci., 24:79(9):890-7, 2006.

Stathatos, N. Anatomy and Physiology of the Thyroid Gland. Clinical Correlates to Thyroid Cancer. In: Wartofsky, L. \& Van Nostrand, D. Thyroid Cancer: A Comprehensive Guide to Clinical Management, $2^{\text {nd }}$ Ed. Totowa, Humana Press Inc., 2006. pp.3-7.

\author{
Drirección para Correspondencia: \\ Dr. Guillermo Salgado Alarcón \\ Facultad de Medicina \\ Pontificia Universidad Católica de Chile \\ Santiago \\ CHILE
}

Email: gsalgado@puc.cl

Recibido : 09-01-2011

Aceptado: 23-02-2011 